\title{
83. Über die Lage, Form und Grösse des Gehörorgans bei den Japanern.
}

\author{
Von Kanoe Nishimura.
}

Anatomisches Institut der Kaiserlichen Universität in Tokyo und der Universitätsklinik für Ohren-, Nasen- und Halskrankheiten.

(Comm. by Y. KoganeI, M.I.A., June 12, 1929.)

Bisher sind meistens die einzelnen Teile des menschlichen Gehörorgans Gegenstand gesonderter Untersuchungen gewesen. In vorliegender Arbeit soll versucht werden, ob irgend welche bestimmten Beziehungen zwischen den einzelnen Teilen und auch zwischen diesen und dem ganzen Schädel existieren. Zu diesem Zwecke wurden Präparate angefertigt, die alle Teile des Gehörorgans von der Ohrmuschel bis zum inneren Ohr zusammenhängend in natürlicher Lage in der Schädelbasis darstellen.

Als Material dienten die Köpfe von 20 Leichen. Nachdem erst die Köpfe und die Ohrmuscheln gemessen und ein Gipsabguss der Ohrmuschel abgenommen wurde, stellte die Verfasserin den Metallausguss des äusseren Gehörganges bis zur Muschelhöhle her, wozu die Lipowitzsche Legierung (Schmelzpunkt $60^{\circ}-65^{\circ} \mathrm{C}$ ) gebraucht wurde. Um den Metallausguss wieder herauszunehmen, muss die untere Wand des äusseren Gehörganges abgemeisselt werden. Dann wurden die Schädel, an denen das Dach horizontal und die Basis median-sagittal durchsägt waren, mazeriert. An den mazerierten Schädeln wurden die nötigen anthropologischen und otologischen Messungen vorgenommen, darauf die Pars petrosa des Schläfenbeins nebst Mastoidealfortsatz herausgesägt. Um den Metallausguss des Felsenbeins zusammen mit dem Mastoidealfortsatz herzustellen, wurde dieses eine genügende Zeit (etwa 10 Stdn.) lang in die geschmolzene Metallmasse hineingelegt, wobei diese in alle Lücken desselben eindringt und zugleich eine metallene Stütze an der unteren Seite des Felsenbeins gebildet wird, welche mit der Metallmasse im äusseren Gehörgange und in der Paukenhöhle, sowie durch die beiden Fenster mit der des Labyrinths zusammenhängt. Nachdem mit einem erhitzten Spatel die hinderliche Metallmasse an der Oberfläche abgekratzt war, wurde nun das metallhaltige Felsenbein mit dem Mastoidealfortsatz in seine ursprüngliche Lage in der Schädelbasis zurückgebracht, und die ganze Schädelbasis auf eine Gipsunterlage fixiert. Nachdem der Gipsklotz vollständig getrocknet war, wurde das Felsenbein wieder herausgenommen und das mittlere etwa $2 \mathrm{~cm}$ lange Stück, das das Labyrinth beherbergt, herausgesägt. Durch Korrodie- 
rung dieses Felsenbeinstücks erhält man den Metallausguss des knöchernen Labyrinths. Diesen Ausguss kann man dadurch in situ an der Schädelbasis fixieren, dass die Metallstütze unter dem Ausgusse in die Gipsunterlage hineinpasst. An der Hand solcher mit grosser Mühe hergestellter Präparate ganz eigener Art wurden die Lage-, Form- und Grössenverhältnisse der einzelnen Teile des Gehörorgans untereinander, sowie zum ganzen Schädel nach verschiedenen Gesichtspunkten hin studiert.

In diesem kurzen Auszuge kann die Verf. unmöglich alle Ergebnisse erwähnen, will daher nur die Lageverhältnisse der drei Bogengänge im folgenden kurz zusammenfassen.

1. Die Kuppe des äusseren Bogenganges liegt fast immer in der gleichen Ebene mit der Ohraugen-Ebene des Kopfes.

2. Die Verbindungslinie der Kuppen der beiderseitigen äusseren Bogengänge liegt etwa $1 \mathrm{~cm}$ hinter der Verbindungslinie der beiden Tragionen.

3. Der Inklinationswinkel des äusseren Bogenganges schwankt zwischen $0^{\circ}$ und $22^{\circ}$ (Schönemann $0^{\circ}$ und $30^{\circ}$ ). Der Winkel ist grösser auf der rechten Seite, bei Frauen grösser als bei Männern und bei Brachykephalie grösser als bei anderen Schädelformen.

4. Der Deklinationswinkel des oberen Bogenganges ist fast immer grösser auf der linken Seite, bei Frauen grösser als bei Männern und bei Mesokephalie grösser als bei anderen Schädelformen.

5. Der Deklinationswinkel des hinteren Bogenganges ist grösser auf der rechten Seite und bei Dolichokephalie.

Über die Lageverhältnisse der drei Bogengänge siehe Tabelle. 


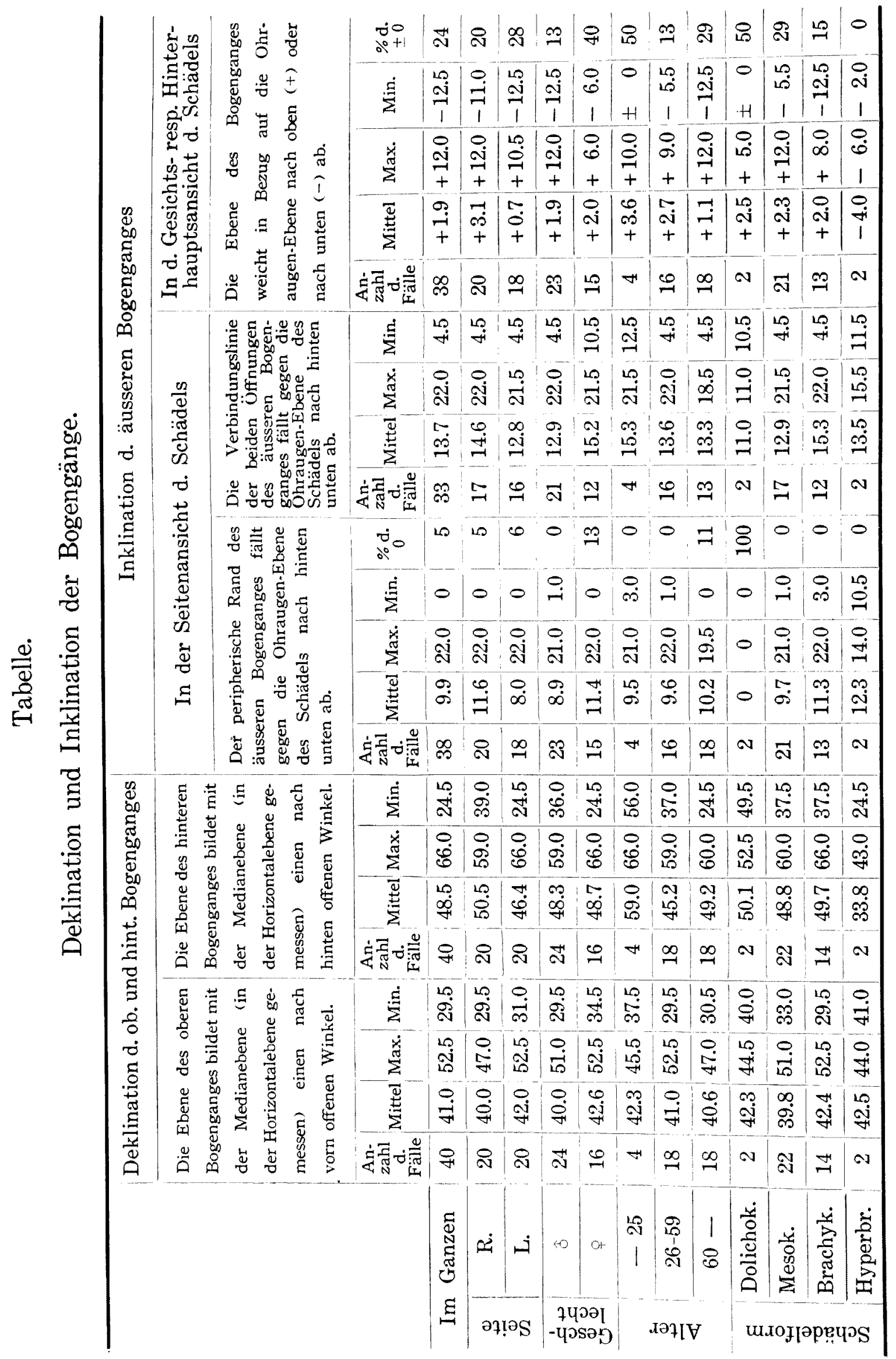

